\title{
Determination of Organochlorine Pesticides in Soil Using PHWE-SPE-SPME/GC-ECD Method
}

\author{
Mirela MICLEAN*, Lăcrimioara ȘENILĂ, Oana CADAR, Erika LEVEI and \\ Marius ROMAN
}

INCDO-INOE 2000, Research Institute for Analytical Instrumentation, 67 Donath Street, 400293, Cluj-Napoca, Romania

${ }^{*}$ Corresponding author, e-mail: mirela.miclean@icia.ro

Bulletin USAMV series Agriculture 71(2)/2014

Print ISSN 1843-5246; Electronic ISSN 1843-5386

DOI 10.15835/buasvmcn-agr: 10360

\begin{abstract}
A method based on pressurized hot water extraction (PHWE), followed by solid phase extraction (SPE) coupled with solid phase microextraction (SPME) and determination by gas chromatography-electron capture detection (GC-ECD) was developed for determination of 19 organochlorine pesticides (OCPs) $(\alpha-, \beta-, \gamma-, \delta$, $\varepsilon$-isomers of hexachlorocyclohexane, 4,4'-DDE, 2,4'-DDE, 4,4'-TDE, 2,4'-TDE, 2,4'-DDT and 4,4'-DDT, aldrin, dieldrin, heptachlor, heptachlor epoxide isomer $\mathrm{A}$, heptachlor epoxide isomer $\mathrm{B}, \alpha$-endosulfan, $\beta$-endosulfan and hexachlorobenzene) in soil. The limits of detection were between $1.69 \mathrm{ng} / \mathrm{kg}$ for hexachlorobenzene and $50.4 \mathrm{ng} / \mathrm{kg}$ for 4,4'-DDT. The analytical method was applied for determination of OCPs in soil samples, collected in Cluj-Napoca area, Romania. Levels of OCPs were determined in five soil samples collected in rural area near Cluj-Napoca, Romania using the PHWE-SPE-SPME/GC-ECD method. OCPs were detected in all of the samples, with a total concentration ranging from 1.99 to $7.85 \mu \mathrm{g} / \mathrm{kg}$. The most predominant compounds were $\mathrm{HCH}$ and DDT isomers.
\end{abstract}

Keywords: $O C P s, P H W E$, soil, $S P E, S P M E$

\section{INTRODUCTION}

Agricultural soils are the major sources of organochlorine pesticides (OCPs) as it acts as an ultimate repository of current and past residues (Sultana et al., 2014). OCPs are notoriously toxic and persistent contaminants, which accumulate in environment. Concern over levels of OCPs and their estrogenic effects has been increasing in recent years (Tsai, 2010). In the environment, sensitive analytical methods are required for their determination.

Classical analytical methods used for determination of OCPs in soil samples have many drawback, among them thay are very time consuming and require relatively large quantities of solvents (Wang and Weller, 2006). In the last years, analytical methods tended towards simplification, miniaturisation and improvement of sample extraction methods with universal microextraction procedures. Among these extraction and cleanup methods, solid phase extraction (SPE) and solid phase microextraction (SPME) have become popular techniques. SPME is an inexpensive, environment-friendly and solvent-free technique with reliable and excellent sensitivity, as well as good selectivity (Merib, 2013).

The aim of this study was to develop a method for OCPs determination in soil using a pressurized hot water extraction (PHWE), followed by SPE coupled with SPME and determination by gas chromatography-electron capture detection (GC-ECD) and to apply this method on real soil samples collected in Cluj County, Romania. The proposed method is based on the combination of the following analytical methods:

PHWE followed by SPME and determination by gas chromatography-mass spectrometry (GCMS) method for the analysis of organochlorine pesticides in sediment samples, reported by Concha-Graña et al. (2010), 
SPE followed by SPME to concentrate pesticides and determination by GC-MS in water samples, reported by Bonansea et al. (2013).

\section{MATERIAL AND METHODS}

\section{Reagents and instrumentation}

Solvents (dichoromethane, methanol, acetonitrile) were gas chromatography grade of quality (Merck, Darmstadt, Germany). Standards solution consists in $\alpha-, \beta-, \gamma-, \delta$-isomers of hexachlorocyclohexane (expressed as HCHs), 4,4'-DDE, 2,4'DDE, 4,4'-TDE, 2,4'-TDE, 2,4'-DDT and 4,4'-DDT (expressed as DDTs), aldrin, dieldrin, heptachlor, heptachlor epoxide (isomer A), heptachlor epoxide (isomer $\mathrm{B}$ ), $\alpha$-endosulfan, $\beta$-endosulfan and hexachloro-benzene (HCB) (LGC Standards, Germany).

The instrumentation used consists in:

- Parr high pressure reactor (Parr Instrument Company, USA) with stirring.

- Agilent Technologies (USA) 6890N gas chromatograph (GC) with electron-capture detector ( $\mu$-ECD) equipped with a capillary column DB$608,30 \mathrm{~m} \times 0.32 \mathrm{~mm}$ ID $\times 0.50 \mu \mathrm{m}$ (Agilent J\&W) High purity Helium was used as carrier gas.

- Ultrapure water system, $18.2 \mathrm{M} \Omega \mathrm{cm}$, Millipore MilliQ DI (France)

For the SPME extraction a manual fiber holder with a $65 \mu \mathrm{m}$ PDMS/DVB fiber type from Supelco Inc. (Bellefonte, PA, USA) were used. Prior to analysis, the fiber was conditioned in the GC inlet for $1 \mathrm{~h}$ at $280^{\circ} \mathrm{C}$.

\section{PHWE procedure}

An amount of $10 \mathrm{~g}$ clean soil spiked with standard solution containing all analytes at 50 $\mu \mathrm{g} / \mathrm{kg}$ was extracted in $1 \mathrm{~L}$ ultrapure water. The extraction was performed at 1500 psi and $150{ }^{\circ} \mathrm{C}$ during $10 \mathrm{~min}$ in the Parr high pressure reactor.

\section{SPE procedure}

The extract obtained after PHWE was concentrated on a Lichrolut C18 cartridge, previously conditioned with dichoromethane, methanol and ultrapure water. Retained analytes were eluted with methanol followed by acetonitrile. The elutes were collected in $10 \mathrm{~mL}$ SPME glass vials, evaporated under nitrogen current until dryness and capped with PTFE-coated septa.

\section{HS-SPME procedure}

The SPME extractions were performed by immersing the SPME fiber in the SPE extract dissol- ved in $100 \mu \mathrm{L}$ of acetone and $6900 \mu \mathrm{L}$ of ultrapure water, at $60^{\circ} \mathrm{C}$ during $45 \mathrm{~min}$.

\section{GC- $\mu$ ECD analysis}

After the extractions, the fiber was desorbed in the GC injector at $280^{\circ} \mathrm{C}$ for $5 \mathrm{~min}$. The GC- $\mu \mathrm{ECD}$ was operated in splitless mode, at $280^{\circ} \mathrm{C}$. The oven temperature program consists of 4 stages: from $80^{\circ} \mathrm{C}$ to $196^{\circ} \mathrm{C}$ (rate $4^{\circ} \mathrm{C} / \mathrm{min}, 2 \mathrm{~min}$ ), from $196^{\circ} \mathrm{C}$ to $224^{\circ} \mathrm{C}$ (rate $4^{\circ} \mathrm{C} / \mathrm{min}, 2 \mathrm{~min}$ ), from $224^{\circ} \mathrm{C}$ to $240^{\circ} \mathrm{C}$ (rate $4^{\circ} \mathrm{C} / \mathrm{min}, 2 \mathrm{~min}$ ) and from $240^{\circ} \mathrm{C}$ to $275^{\circ} \mathrm{C}$ (rate $4^{\circ} \mathrm{C} / \mathrm{min}, 2 \mathrm{~min}$ ). Detector temperature was set at $300^{\circ} \mathrm{C}$.

\section{RESULTS AND DISCUSSION}

For the validation, the following figures of merit were determined: linearity, limit of detection/quantification, recovery and repeatability. Linearity was examined in the range $1.5-100 \mathrm{ng} /$ kg. Calibration was performed using external standard calibration curve with 6 concentration levels $(1.5 ; 5.0 ; 10 ; 25 ; 50 ; 100 \mathrm{ng} / \mathrm{kg})$ of OCPs, prepared in the sample matrix using the analytical procedure for extraction and chromatographic determination described above. The standard solutions were prepared by diluting accurate volumes of OCPs in n-hexane. The limits of detection and quantification values were estimated experimentally using a signal-to-noise ratio of 3 and 10, respectively.

The accuracy of the method was determined in terms of recovery experiments by extracting the OCPs from spiked soil samples, prepared by adding adequate volumes of working solution to $10 \mathrm{~g}$ of blank matrix. The precision, expressed as the repeatability (\% RSD) was determined by three consecutive extractions of OCPs from spiked soil samples, at a concentration of $20 \mathrm{ng} / \mathrm{kg}$ OCPs. The values obtained for the method's figures of merit are shown in Table 1.

External standard calibration revealed correlation coefficients (r) higher than 0.995, except for 4,4'-DDD. The obtained LOQs ranged between $1.69-50.4 \mathrm{ng} / \mathrm{kg}$ for all the investigated pesticides. Because the analytes are concentrated onSPEcartridgeand on theSPME fiber and is rapidly delivered to the column, minimum detection limits are achieved. Satisfactory quantitative recoveries of $68-90.1 \%$ were obtained. Precisions were above $9.55 \%$, the highest value being recorded for $2,4^{\prime}$-DDT $(20.9 \%)$. We considered that the most quality requirements (high sensitivity, accuracy 
Tab. 1. Figures of merit for PHWE-SPE-SPME/GC-ECD method validation in soil samples

\begin{tabular}{ccccccc}
\hline $\begin{array}{l}\text { Crt. } \\
\text { No. }\end{array}$ & Compound & $\begin{array}{c}\text { Correlation } \\
\text { coefficient, } \mathrm{r}\end{array}$ & $\begin{array}{c}\text { Limit of } \\
\text { detection, } \\
\text { LOD } \\
(\mathrm{ng} / \mathrm{kg})\end{array}$ & $\begin{array}{c}\text { Limit of } \\
\text { quantification, } \\
\text { LOQ } \\
(\mathrm{ng} / \mathrm{kg})\end{array}$ & $\begin{array}{c}\text { Recovery } \\
(\%)\end{array}$ & $\begin{array}{c}\text { RSD } \\
(\%)\end{array}$ \\
\hline 1 & $\alpha$-HCH & 0.9963 & 1.87 & 5.96 & 72.8 & 12.8 \\
\hline 2 & $\beta$-HCH & 0.9958 & 3.02 & 10.5 & 80.5 & 10.2 \\
\hline 3 & $\begin{array}{c}\text { Hexachloro- } \\
\text { benzene }\end{array}$ & 0.9990 & 0.50 & 1.69 & 75.5 & 11.5 \\
\hline 4 & $\gamma$-HCH & 0.9970 & 4.18 & 13.8 & 81.3 & 15.1 \\
\hline 5 & $\delta$-HCH & 0.9966 & 6.53 & 21.0 & 88.9 & 11.2 \\
\hline 6 & $\varepsilon$-HCH & 0.9961 & 9.11 & 29.7 & 90.1 & 9.55 \\
\hline 7 & Heptachlor & 0.9956 & 11.6 & 38.2 & 88.6 & 16.7 \\
\hline 8 & Aldrin & 0.9979 & 3.67 & 12.01 & 72.2 & 13.2 \\
\hline 9 & Heptachlor epoxide B & 0.9959 & 1.96 & 6.78 & 76.9 & 9.87 \\
\hline 10 & Heptachlor epoxide A & 0.9956 & 4.07 & 13.7 & 81.6 & 11.0 \\
\hline 11 & $2,4^{\prime}$-DDE & 0.9961 & 7.11 & 24.1 & 79.2 & 12.1 \\
\hline 12 & $\alpha$-Endosulfan & 0.9972 & 4.87 & 16.7 & 85.3 & 14.8 \\
\hline 13 & $4,4^{\prime}$-DDE & 0.9959 & 6.22 & 21.4 & 78.4 & 11.2 \\
\hline 14 & $2,4^{\prime}$-DDD & 0.9960 & 12.0 & 40.1 & 76.8 & 15.9 \\
\hline 15 & Dieldrin & 0.9972 & 4.27 & 15.3 & 83.7 & 16.9 \\
\hline 16 & $\beta$-Endosulfan & 0.9965 & 2.47 & 9.11 & 78.6 & 13.9 \\
\hline 17 & $4,4^{\prime}$-DDD & 0.9911 & 10.4 & 35.3 & 78.6 & 18.4 \\
\hline 18 & $2,4^{\prime}$-DDT & 0.9966 & 9.32 & 31.5 & 71.3 & 20.9 \\
\hline 19 & $4,4^{\prime}$-DDT & 0.9954 & 17.2 & 50.4 & 75.9 & 15.8 \\
\hline
\end{tabular}

Tab.2. Concentrations of OCPs in soil samples collected in Cluj County, Romania ( $\mu \mathrm{g} / \mathrm{kg}$ )

\begin{tabular}{ccccccc}
\hline $\begin{array}{l}\text { Crt. } \\
\text { No. }\end{array}$ & Compound & 1 & 2 & 3 & 4 & 5 \\
\hline 1 & $\alpha$-HCH & 0.74 & 1.83 & 0.58 & 0.83 & 0.48 \\
\hline 2 & $\beta$-HCH & 0.10 & 0.09 & $<$ LOQ & 0.04 & 0.07 \\
\hline 3 & Hexachloro- benzene & 0.02 & 0.14 & 0.04 & 0.12 & 0.13 \\
\hline 4 & $\gamma$-HCH & 0.44 & 0.43 & 0.22 & 0.25 & 0.19 \\
\hline 5 & $\delta$-HCH & 0.34 & 0.18 & 0.16 & 0.16 & 0.15 \\
\hline 6 & $\varepsilon$-HCH & 3.77 & 0.08 & 0.03 & 0.05 & $<$ LOQ \\
\hline 7 & Heptachlor & $<$ LOQ & 0.16 & 0.05 & 0.02 & $<$ LOQ \\
\hline 8 & Aldrin & 0.06 & 0.04 & $<$ LOQ & $<$ LOQ & 0.05 \\
\hline 9 & Heptachlor epoxide B & $<$ LOQ & $<$ LOQ & $<$ LOQ & $<$ LOQ & 0.02 \\
\hline 10 & Heptachlor epoxide A & 0.15 & 0.17 & 0.14 & $<$ LOQ & 0.05 \\
\hline 11 & $2,4^{\prime}$-DDE & 0.23 & 1.96 & 0.33 & 0.88 & 0.16 \\
\hline 12 & $\alpha$-Endosulfan & 0.05 & $<$ LOQ & 0.12 & $<$ LOQ & $<$ LOQ \\
\hline 13 & $4,4^{\prime}$-DDE & 0.63 & 1.13 & 0.1 & 0.18 & 0.04 \\
\hline 14 & $2,4^{\prime}$-DDD & 0.10 & 0.06 & 0.06 & 0.04 & 0.02 \\
\hline 15 & Dieldrin & 0.19 & $<$ LOQ & 0.07 & $<$ LOQ & 0.10 \\
\hline 16 & $\beta$-Endosulfan & 0.05 & 0.03 & $<$ LOQ & 0.02 & 0.04 \\
\hline 17 & $4,4^{\prime}$-DDD & 0.14 & 0.22 & 0.09 & 0.15 & 0.11 \\
\hline 18 & $2,4^{\prime}-$ DDT & 0.06 & 0.12 & 0.03 & 0.12 & $<0.05$ \\
\hline 19 & 4,4'-DDT & 0.25 & 1.21 & 0.37 & 1.08 & 0.38 \\
\hline
\end{tabular}


and precision) were accomplished regarding the studied parameters.

The developed method, PHWE-SPE-SPME/ GC-ECD was applied on 5 real surface soil samples collected in September 2013 in rural areas in Cluj County, Romania. The obtained concentrations of OCPs using PHWE-SPE-SPME/GC-ECD method are shown in Table 2.

In all the investigated soil samples, OCPs were detected. The highest concentration and occurrence were determined for the $\mathrm{HCH}$ isomers $(\alpha-\mathrm{HCH}, \gamma-\mathrm{HCH}, \delta-\mathrm{HCH}$ and $\varepsilon-\mathrm{HCH})$ and DDT isomers (2,4'-DDE, 4,4'-DDE, 4,4'-DDT, 4,4'DDD). Hexachlorobenzene and 2,4'-DDD were determined also in all the analyzed samples. Heptachlor epoxide A, $\beta$-endosulfan and $\beta$-HCH were detected in 4 from 5 samples. The obtained concentrations were lower than the threshold values set by Romanian legislation in the Ministerial Order No. 756/1997 - Order of the Ministry of waters, forests and environment protection for the approval of the Regulation on environmental pollution assessment.

\section{CONCLUSIONS}

A method for the analysis of 19 OCPs in soil at trace levels by PHWE-SPE-SPME/GC-ECD was developed. The quality requirements were accomplished for most analysed compounds. The proposed method is rapid, highly sensitive, ecological and represents an alternative to conventional techniques.

OCPs were detected in all the collected soil samples in Cluj County rural area, but the concen- trations were lower than the thresholds set by Romanian legislation.

Acknowledgement: This work was supported by Romanian financing authority UEFISCDI, Capacities, Romania-Austria bilateral cooperation project, project number 751/2014.

\section{REFERENCES}

1. Bonansea RI, Amé MV, Wunderlin DA (2013). Determination of priority pesticides in water samples combining SPE and SPME coupled to GC-MS. A case study: Suquía River basin (Argentina), Chemosphere 90:18601869.

2. Concha-Grańa E, Fernández-González V, Grueiro-Noche G, Muniategui-Lorenzo S, López-Mahía P, FernándezFernández E, Prada-Rodríguez D (2010). Development of an environmental friendly method for the analysis of organochlorine pesticides in sediments, Chemosphere 79: 698-705.

3. Merib J, Simão V, Neves Dias A, Carasek E (2013). Simultaneous determination of trihalomethanes and organochlorine pesticides in water samples by direct immersion-headspace-solid phase microextraction, J Chrom A 1321:30- 37.

4. Sultana J, Hussain Syed J, Mahmood A, Ali U, Abdur Rehman MY, Malik RN, Li J, Zhang G (2014). Investigation of organochlorine pesticides from the Indus Basin, Pakistan: Sources, air-soil exchange fluxes and risk assessment, Sci Tot Environ 497-498:113-122.

5. Tsai W-T, 2010, Current Status and Regulatory Aspects of Pesticides Considered to be Persistent Organic Pollutants (POPs) in Taiwan, Int J Environ Res Public Health $7(10): 3615-3627$.

6. Wang L, Weller CL (2006). Recent advances in extraction of nutraceuticals from plants, Trends Food Sci Technol 17:300-312. 